Conflicto y acceso a la vivienda

\title{
El desplazamiento forzado intraurbano: una modalidad de movilidad residencial a las coacciones controvertidas
}

\author{
Intra-Urban Forced Displacement: A Residential Form of \\ Mobility Induced by Controversial Constraints
}

O deslocamento forçado intra-urbano: uma modalidade de mobilidade residencial às coações controvertidas

Tiphaine Duriez*

Recibido: 15 de enero de 2018

Aprobado: 6 de agosto de 2018

Doi: http://dx.doi.org/10.12804/revistas.urosario.edu.co/territorios/a.6402

Para citar este artículo:

Duriez, T. (2019). El desplazamiento forzado intraurbano: una modalidad de movilidad residencial a las coacciones controvertidas. Territorios (40), 245-272. Doi: http://dx.doi.org/10.12804/revistas.urosario. edu.co/territorios/a.6402 * Doctora en etnologia,
Université Nice-SophiaAn-
tipolis (Francia). Profesora
de antropologia, Univer-
sidad Lyon 2 - Lumières
LADEC (FRE 2002). Inves-
tigadora asociada, URMIS
(CNRS UMR 8245-IRD UMR
205). Correo electrónico:
tiphaine.duriez@univ-
lyon2.fr ORCID: http://or-
cid.org/O000-0002-1306-
5749
Marc Marti, Profesor deli-
teratura y civilización es-
pañola de la Universidad
Nice Côte d'Azur LIRCES
(EA 3159 ) realizó la revi-
sión en español. 
Palabras clave

Migración forzada, conflicto armado interno, control de territorios, espacios urbanos informales, violencia, transferencia y transposición de las dinámicas armadas.

Keywords

Forced migration, internal armed conflict, territorial control, informal urban settlements, violence, transfer and implementation of armed dynamics.

Palavras-chave Migração forçada, conflito armado interno, controle de territórios, espaços urbanos informais, violência, transferência e transposição das dinâmicas armadas.

\section{territarias 40}

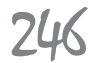

\section{RESUMEN}

Los conflictos armados y las guerras de nuestros mundos contemporáneos han de ser analizados sin ambigüedad: para los civiles, estos enfrentamientos van acompañados de movimientos masivos de población. En la gran mayoría de los casos, estos flujos migratorios se producen dentro de las fronteras nacionales y, en este contexto, Colombia ocupa un lugar particular. Durante casi siete décadas, este territorio andino ha sido atravesado por diversas formas de reivindicaciones y enfrentamientos armados. Así, más allá de la finalización del Proceso de Paz iniciado en 2011, este país cuenta actualmente con más de 7,7 millones de desplazados internos según ACNUR (2018). Desde 1997, el gobierno colombiano ha adoptado una serie de medidas políticas para compensar a quienes representan a la mayoría de sus víctimas civiles de la guerra: los desplazados forzados. Enfocando la construcción de este estatuto, cuyo objetivo primero fue indemnizar la inestabilidad socioeconómica engendrada por la importancia de estos flujos migratorios, este artículo propone examinar los nexos existentes entre la ciudad y la guerra para presentar las reconfiguraciones urbanas del desplazamiento forzado. El análisis partirá de la definición del término 'desplazamiento forzado', tal como se entiende en Colombia para apoyar el enfoque territorial aplicado a este tipo de movilidad forzada politizada. El trabajo de tesis base de este artículo se centró alrededor de estos temas y, específicamente, en las situaciones observadas dentro de las Comunas 4 y 6 de Soacha, situaciones que servirán para ilustrar el argumentario.

\section{ABSTRACT}

Contemporary armed conflicts and wars must be analyzed without ambiguity: for civilians, these confrontations produce massive population movements. In most cases, these migratory flows within national borders. In this context, Colombia assumes a special place. For nearly seven decades, this Andean territory has been crossed by various forms of claims and armed confrontations. Thus, despite the result of the peace process initiated in 2011 , nowadays and according to ACNUR (2018), the country has over 7.7 million internally displaced persons. Since 1997, the Colombian government has passed a series of political measures to compensate those who represent most of its civilian war victims: the so called desplazados forzados. This article proposes to examine the reconfigurations of the urban forced displacement movements focusing on the construction of this status and on the links between the city and the war. The main objective of the "desplazamiento forzado" law aimed to compensate the socio-economic instability generated by these migratory flows. From there, the analysis will start by defining the "forced displacement" as it is conceived in the Colombian context to discuss the territorial approach applied to this type of politicized forced mobility. Mi PhD work focused on these issues, and more particularly on the situations observed in the 4th and 6th districts of the municipality of Soacha, whose data will be used to illustrate the remarks made in this article.

\section{RESUMO}

Os conflitos armados e as guerras de nossos mundos contemporâneos têm de ser analisados sem ambiguidade: para os civis, estes enfrentamentos vão acompanhados de movimentos massivos de população. Na grande maioria dos casos, estes fluxos migratórios se produzem dentro das fronteiras 
nacionais e neste contexto, a Colômbia ocupa um lugar particular. Durante quase sete décadas, este território andino tem sido atravessado por diversas formas de reivindicações e enfrentamentos armados. Assim, para além da finalização do processo de paz iniciado em 2011, este país conta atualmente com mais 7,7 milhões de deslocados internos segundo ACNUR (2018). Desde 1997, o governo colombiano tem adotado uma série de medidas políticas para compensar a quem representam à maioria de suas vítimas civis da guerra: os deslocados forçados. Focando a construção deste estatuto, cujo objetivo primeiro foi indemnizar a instabilidade socioeconômica engendrada pela importância destes fluxos migratórios, este artigo propõe examinar os nexos existentes entre a cidade e a guerra para apresentar as reconfigurações urbanas do deslocamento forçado. A análise partirá da definição do termo "deslocamento forçado" tal como se entende na Colômbia para apoiar o enfoque territorial aplicado a este tipo de mobilidade forçada politizada. Meu trabalho de tese centrou-se ao redor destes temas, e especificamente nas situações, observadas dentro das Comunas 4 e 6 de Soacha, situações que servirão a ilustrar o argumentário.

\section{Introducción}

Este artículo es el resultado de un trabajo de tesis de etnología realizado entre 2010 y 2014 en el Laboratorio Interdisciplinario de Narrativas, Culturas y Sociedades (LIRCES, EA 3159) de la Universidad NiceSophia Antipolis-UCA JEDI. Se basa en trabajos de campo que se iniciaron antes de la tesis, durante la investigación de máster. Se realizaron con regularidad entre 2008 y 2012, primero en Medellín y luego en Soacha, municipio periférico de Bogotá, capital de Colombia. Basado en un trabajo cualitativo situacional (Gluckman, 1958) y multi-situ (Marcus, 1995) que sumió, en más de un año de investigaciones, unas cuarenta entrevistas, entre de las cuales veinte pudieron ser grabadas, el objetivo de este trabajo fue estudiar las modalidades urbanas de un fenómeno migratorio que, aunque se produce en muchos países en guerra, tiene una dimensión particular en el contexto armado colombiano: el desplazamiento forzado por la violencia. Iniciar un estudio sobre este tema no era nuevo en sí; la inclusión de esta investigación en un espacio urbano, sin embargo, la diferenciaba de lo que se había realizado mayoritariamente hasta entonces sobre esta modalidad migratoria politizada.

De hecho, si bien, se reconoce que los desplazamientos forzados están muy extendidos en las zonas rurales de Colombia, existe una renuencia a reconocer su existencia en las ciudades, como lo demuestran unos estudios que enfocan sus modalidades urbanas. Estas diferencias de discurso despertaron el interés de la investigación y motivaron a emprender un complejo proceso de investigación, cuyo propósito era identificar razones prácticas y simbólicas de las reservas expresadas sobre la existencia de una dimensión urbana del desplazamiento forzado. Para estudiar este fenómeno, se favoreció un enfoque por el territorio. De hecho, este era el común denominador de la discordia narrativa territarias 40 247 
${ }^{1}$ Con respecto a Medellín, es uno de los primeros municipios que se ha enfrentado con casos masivos de desplazamientos forzados intra-urbanos y que ha establecido arreglos institucionales específicos para responder a la práctica de esta modalidad de migración forzada (Londoño, 2007). Sin embargo, las dificultades identificadas en el campo durante la investigación de máster de la investigación inicial, Comuna 13 , incitaron a cambiar el espacio, y fue en los Altos de Cazucá, en Soacha, donde se decidió realizar la tesis doctoral, esta comunidad también presenta muchos casos de desplazamiento forzado intra-urbano.

\section{territarias 40} 248 observada. Así pues, el método no procedió por muestreo de una población de 'alto riesgo', sino por 'espacialización' de un fenómeno migratorio que se producía en las denominadas zonas de 'alto riesgo', en las que se basaban los sitios seleccionados, según este criterio para la encuesta de esta investigación ${ }^{1}$. A partir de entonces, el proceso de investigación consistió en reunirse con diversas instituciones gubernamentales y no gubernamentales involucradas en las estrategias para el cuidado de desplazados forzados. La expectativa era doble: por un lado, recopilar sus discursos sobre las modalidades urbanas de estas movilidades bajo coacciones $\mathrm{y}$, por otro lado, poder acceder a los espacios y relatos de las poblaciones enfrentadas con estas prácticas de desalojo forzoso desde una postura de intrusa-incluida. Si bien, el análisis narrativo reveló las razones de las interpretaciones divergentes observadas con respecto a los desplazamientos forzados intra-urbanos, las observaciones in situ realizadas en los lugares donde se registraron estos desalojos forzados pusieron de manifiesto su vinculación con el conflicto armado interno.

Este artículo propone, pues, presentar parte de los resultados de esta encuesta situando el tema de la ciudad en el centro del análisis. Se reconoce políticamente que el contexto armado colombiano fomentó el desarrollo de una práctica intensa y sostenida de desplazamiento forzado de la población. La hipótesis era que las razones de la retórica antagónica que se observaba en cuanto a su extensión urbana descansaban de las múltiples lecturas de los entresijos del conflicto armado interno o de un problema epistemológico relacionado con lo que se entendía por 'ciudad'. Para responder a esta pregunta, el proceso de investigación se dividió en dos etapas. Una primera etapa de la investigación se centró en establecer lo que se entendía por desplazamiento forzado por la violencia, fase que enfoca la primera parte de este artículo. Una vez establecidas estas bases, la segunda fase de la encuesta permitió concentrarse en la observación del tratamiento político de este tipo de movilidad forzada, centrándose en el enfoque territorial que se le aplicaba. La segunda parte del artículo vuelve a este aspecto, analizando el lugar que ocupan las ciudades en el desarrollo de esta práctica migratoria. En Colombia, las áreas urbanas han sido consideradas durante mucho tiempo como zonas de refugio para la expansión y generalización de desplazamientos forzados. Por lo tanto, tienen un vínculo específico con este tipo de movilidad forzada, pero no significa que estén exentos de violencia. La tercera parte del artículo cuestiona este vínculo, analizando, según un enfoque situacional, los casos de desplazamientos forzados intraurbanos identificados durante el trabajo de campo.

\section{El desplazamiento forzado, una modalidad de migración politizada por el ejercicio de la guerra}

Antes de presentar las modalidades urbanas de desplazamiento forzado en Colombia, 
es necesario volver a lo que se entiende por este término. Si esta modalidad de migración bajo coacción no es exclusiva de este país, tiene una dimensión particular cuya explicación se debe a dos factores. La primera es histórica: si la práctica de desplazamientos forzados alcanzó su paroxismo en los años 2000 (Salcedo, 2015), acompañó los enfrentamientos armados que azotan este territorio desde mediados del siglo XX. El segundo es político: el uso de este término se refiere a una Ley ratificada por el gobierno colombiano en 1997, que establece que:

es desplazado toda persona que se ha visto forzada a migrar dentro del territorio nacional abandonando su localidad de residencia o actividades económicas habituales, porque su vida, su integridad física, su seguridad o libertad personales han sido vulneradas o se encuentran directamente amenazadas con ocasión de cualquiera de las siguientes situaciones: conflicto armado interno; disturbios y tensiones interiores, violencia generalizada, violaciones masivas de los Derechos Humanos, infracciones al Derecho Internacional humanitario u otras circunstancias emanadas de las situaciones anteriores que puedan alterar drásticamente el orden público (Senado de la República de Colombia, 1997, Ley 387).

El estudio del desplazamiento forzado constituye un tema de investigación interdisciplinar ${ }^{2}$, así que invita a considerar tanto las múltiples dimensiones del conflicto armado interno que afectan a este país como la construcción de una categoría migratoria relacionada con el ejercicio de la guerra. Junto a la tipología de los movimientos forzados dentro de las fronteras nacionales, el uso de este término describe tanto como prescribe una dinámica particular de movimiento de la población. Además, su declaración forma parte de un doble discurso. Hay, por un lado, lo que los migrantes y el gobierno dicen al respecto $y$, por otro lado, la forma en que cada uno se posiciona con respecto al discurso del otro. La mayoría de los ciudadanos colombianos que han vivido esta modalidad migratoria representan más del $14 \%$ de la población nacional, siguiendo una trayectoria migratoria de zonas rurales a urbanas. Sin embargo, esta asombrosa cifra solo refleja los movimientos forzados que, desde 1985, han sido inscritos en el Registro Único de Desplazados (RUPD), que, desde 2011 y tras la ratificación de la Ley 1448 denominada Víctimas y restitución de tierras, se ha convertido en el Registro Único de Víctimas (RUV).

Se vislumbran dos límites. En primer lugar, aunque aún no tenía todavía nombre, la práctica del desplazamiento forzado de la población es anterior a esa fecha. Así, entre 1947 y 1965 "Se estima que 2 millones de personas fueron expulsadas por la violencia y que 393648 parcelas de tierra fueron abandonadas por la violencia o que, más bien, cambiaron de propietario" (Ortiz, 1978, p. 323-324). En segundo lugar, estos datos reflejan el desplazamiento forzado tal como lo representan los funcionarios encargados del registro de
${ }^{2}$ Los trabajos académicos sobre el desplazamiento forzado en Colombia son numerosos y abarcan varias disciplinas de las humanidades y ciencias sociales, desde la antropología a la historia, el derecho, la estadística, la demografía, la psicología, la sociologia, la geografía, las ciencias politicas y los estudios urbanos.

territarias 40 249 
las declaraciones de las víctimas, es decir, como migración iniciada en respuesta a las violencias del conflicto armado interno como se enumeran en la Ley 387 de 1997. Si bien, son pocos los países cuyo poder legislativo han elaborado normas específicas para proteger a las personas desplazadas dentro de su propio país y garantizar el respeto de sus derechos, el Estado colombiano es, en este caso, una excepción. Por medio del Artículo 387, los migrantes víctimas de la guerra adquieren un estatuto específico cuya construcción, elaborada sobre el carácter excepcional de su movimiento (Agamben, 2003), prevé el establecimiento de una política pública de asistencia y protección sin precedentes en el territorio nacional. Pero, si bien esta Ley reconoce la eficacia de las prácticas de desplazamiento forzado en el territorio nacional, la norma codificó la serie de desplazados forzados (Abélès, 2008), a partir del reconocimiento de la violencia que los incitó a huir de su lugar de residencia. Sin embargo, la categoría de violencia es contextual: difusa, inmanente en la sociedad colombiana (Corten \& Côté, 2008) y puede manifestarse tanto físicamente como simbólicamente, verbalmente o psicológicamente, ya sea de manera organizada o desorganizada y directamente (actos/palabras) o indirectamente (escritos/rumores).

Así pues, las causas violentas de la salida de la tierra, promulgadas por la Ley 387 de 1997, no necesariamente son percibidas como tales por quienes las viven. Del mismo modo, los esquemas de deportación que describen, no siempre corresponden a la violencia desdibujada por este texto. Así, los datos cuantitativos producidos sobre este fenómeno reflejan una política de categorización. El registro de la declaración de un ciudadano en las bases de datos gubernamentales depende de su capacidad para adecuar su relato al marco normativo de la Ley 387 de 1997. Esto implica la necesidad de dominar los códigos y compartir información social (Goffman, 1975). Sin embargo, muy a menudo, es solo después de llegar a la ciudad que los civiles obligados a trasladarse a la fuerza se enteran de la existencia del texto, como lo dijo Rosa, desplazada de su aldea antioqueña en 2008, tras el asesinato de su hijo por el grupo Cordillera:

Yo no sabía qué era esto, yo no sabía qué era desplazamiento [...] yo no sabía qué era eso, yo no sabía que a uno el gobierno lo ayudaba, yo no sabía nada de esas cosas [...] cuando yo llegué acá, que llegué así tan mal, pues bueno ahí, el paisano mío pues, yo aquí sin SISBEN ni nada. O sea, él fue a una droguería a comprarme cosas para [... para los morados que tenía en la cara, y por los de por acá (enseña sus costillas). Es que me dieron patadas y todo, pero bueno, me alivié, gracias a Dios. Y ya, después, ahí llegó una vecina, a la casa [...] me la presentaron y bueno $[. .$.$] Y le dije [\ldots]$, a la señora de este paisano, que "Ella viene de $\mathrm{X}$, a ella le paso esto y esto". Y yo miraba [a esta señora] como con miedo. Ella me decía "Tranquilla, que ella es, es como familia mía, y ella

\section{territarias 40}


pues es desplazada". Entonces esta me dijo: “Usted no ha declarado?” y yo dije: “¿Qué es eso?". Me dijo "Pues vea, a usted le mataron a su hijo, la sacaron de su pueblo, eso es desplazamiento forzoso", me dijo ella. Y yo le dije: “¿Y, eso, qué es eso?”. "Pues, usted se va a una UAO, declara [...] pues no pudiste hacerlo allá así que lo declara acá. Y le van a dar una carta de desplazamiento. Y a usted la deben indemnizar por su hijo". Y yo le dije: “¿y eso dónde queda?”. Y esta (la mujer del paisano) me llevó. Pero, entonces, había mucha gente allá, así que no pude declarar. Pero yo declaré en el 2009. Yo no declaré en el 2008. Yo vine en septiembre, y en enero o febrero fue que vine a declarar. [...] Yo declaré porque de verdad, esos son mis derechos y porque lo que viví es un desplazamiento, pero como yo le dije, yo la verdad, yo nunca [...] yo no sabía que eso era un desplazamiento (Rosa, 2012).

Este extracto de entrevista ilustra la existencia de una discrepancia entre lo que normativamente se considera desplazamiento forzado por la violencia y lo que perciben subjetivamente los sujetos que la experimentan. Rosa no "sabía nada" de los desplazados hasta que llegó a los Altos de Cazucá. Se enteró de que lo que había experimentado se llamaba "desplazamiento forzado" por medio de una vecina y explica que había declarado su situación porque tenía "el derecho" a hacerlo. Transcurrió un año entre el momento en que ocurrieron los hechos y su declaración. La historia que cuenta no es excepcional. Las veinte o menos víctimas de desplazamientos forzados que se entrevistaron para esta investigación, sean en Socha, en Medellín o en otras partes de la aglomeración urbana de Bogotá, dieron testimonio de un proceso similar: sus declaraciones se hicieron después de los hechos y por recomendación de un tercero. Desde la perspectiva de los solicitantes del registro, estos elementos permiten argumentar que se está ante un mecanismo discursivo que explica la formación de una subvaloración del fenómeno. Sin embargo, desde la perspectiva del personal encargado de la recopilación y del registro de sus declaraciones, la aclaración de las discrepancias entre las estimaciones tiene otra explicación. En este caso, es la percepción de la violencia lo que causa discordia, porque "está cargada de representaciones compuestas [y se refiere] a fenómenos de naturaleza muy diferente" (Lenclud, Calverie \& Jamin, 1984, p. 11). En este sentido, Todorov afirmó que "no basta con condenar la violencia [...] debemos tratar de entenderla: nunca estalla sin razones" (Todorov, 2008, p.143). Así, nombrar la violencia es una cuestión de percepción. No se deja atrapar. De modo performativo, se califica, glorifica, identifica o rechaza según la inteligibilidad de los intereses que la animan: es situacional en el sentido de que nace "en la tensión [...] de las manipulaciones que provocan determinados órdenes sociales" (Héritier, 2003 , p. 22) para tomar sentido, ajustándose a ellas o regulándolas, en las "matrices de intolerancia" que comparten y que son 
consustanciales con la identidad del grupo, teniendo papel central cuando se trata de identificar lo que es ajeno.

Como se desprende de la difusión de las representaciones cartográficas construidas a partir del análisis estadístico de los datos disponibles sobre los flujos migratorios internos colombianos, existe una fuerte imaginación geográfica que vincula los sitios de desahucio con actores subversivos armados específicos. De hecho, se refieren a 'zonas de desahucio' o 'zonas de expulsión' y 'zonas de recepción' que, aunque permiten vislumbrar los caminos migratorios emprendidos por desplazados, no ilustran en modo alguno la ruta que han seguido. Por lo tanto, no es la posición de 'testigo' la que se toma en cuenta en las declaraciones relativas a estos procesos de deportación: es el testimonio de la experiencia migratoria. Asimismo, para aumentar sus posibilidades de integrarse en el Registro Único de Víctimas (RUV), los ciudadanos que son víctimas del desplazamiento forzado deben asegurarse de que sus relatos correspondan con la representación de las violencias identificadas como ocurridas en sus territorios de desalojo. En este juego de "sedentarismo metafísico" o "metafísica de la sedentaridad" (Malkki, 1997 citado en Monsutti 2004), la atribución del estatuto de desplazado a los migrantes en la guerra se hace según su capacidad en emparejar el grupo armado correcto con el territorio correcto de expulsión. Entonces, ¿̨cómo sortear estas pre-conceptualizaciones de

\section{territarias 40}

1994)? Quizá, invirtiendo el enfoque sobre la migración. Hasta entonces, estos movimientos poblacionales se han abordado principalmente desde el prisma del progreso, y su explicación causal se encuentra en las macroteorías de la modernización y la dependencia que dominaron el análisis demográfico y espacial desde la década de 1930 a 1980. Sin negar estos patrones, el contexto político colombiano es muy diferente y no puede explicar los desplazamientos forzados observados en su territorio como un fenómeno de "migración desde áreas pobres en capital, pero ricas en mano de obra, hacia áreas económicamente prósperas que necesitan muchos trabajadores" (Monsutti, 2004, p. 37).

Si bien, las acciones emprendidas contra la población civil por los actores armados involucrados en el conflicto motivan su salida, no son solo una amenaza letal. Más que un partido de ajedrez, los conflictos armados que se desarrollan internamente se asemejan al juego del Go y, como tal, se basan voluntariamente en una estrategia ofensiva cuyo objetivo es "tomar intacto todo lo que está bajo el cielo. De esta manera [...] (la) victoria será total" (Sun, 2008, p. 143). Por lo tanto, no se trata solo de someter al enemigo a su voluntad (Clausewitz, 1995), sino de aprovechar las disposiciones del terreno teniendo en cuenta sus debilidades para poder perdurar en el tiempo. En la medida en que las tácticas ofensivas de los actores armados involucrados en el conflicto son las de una larga guerra de movimientos que dura en el 
tiempo, el factor económico tiene un papel central en la conducción del combate. De hecho, "Donde está el ejército, los precios son altos; cuando los precios suben, la riqueza del pueblo se agota. Cuando se agotan las riquezas del país, los agricultores se quedan sin recursos" (Sun, 2008, p. 134). Así pues, el impacto socioeconómico de los enfrentamientos sobre las condiciones de vida de los civiles es un factor limitante que justifica su desplazamiento, así como la violencia física a la que pueden ser sometidos.

Como el gran contexto, lleva casi cincuenta años $[\ldots]$ pero bueno, uno no podría negar que la condición de facto del desplazamiento viene desde mediados de los cincuenta, e incluso antes. Y tú puedes encontrar muchas familias que se han desplazado. ¡ $\mathrm{Mu}$ chas! Y su historia intergeneracional es de desplazamiento constante: "mi abuelo se desplazó, mi bisabuelo se desplazó, mis tatarabuelos se desplazaron" [...] bueno casi nunca llegarán a los tatarabuelos, pero por lo menos a los bisabuelos. Y tú puedes identificar como una especie de recorrido en las narrativas de muchas personas en situación de desplazamiento. Ahora, habría que mirar $[\ldots]$ no tanto la foto como está ahora, sino como los procesos históricos, políticos y sociales del conflicto los han llevado a casi naturalizar esta condición. Es decir, es natural desplazarse. No hay lugares de arraigo en el país. [...] Nuestra historia fue un proceso constante de desplazamiento, pero los de ahora fueron formalizados
(Profesor de Antropología, Universidad Javeriana, 2011).

Este extracto de entrevista destaca un punto importante: invita a situar el territorio más que la violencia en el centro del análisis de los desplazamientos forzados. Existen múltiples patrones de desahucios (desalojos individuales o colectivos, anticipados o in situ) y los relatos de las víctimas mencionan diferentes limitaciones (acciones de actores armados paraestatales o estatales, amenazas de reclutamiento forzado, pérdida de actividad económica consuetudinaria en detrimento de una actividad económica impuesta), pero más allá de la singularidad de los contextos a los que han correspondido, estos desahucios tienen un punto común: los que están involucrados en estos procesos tienen que atravesar el espacio nacional buscando un nuevo lugar donde residir. Así, más que la experiencia del conflicto armado como fenómeno, es la relación con el territorio lo que constituye el hilo histórico del desplazamiento forzado. La respuesta institucional formulada en respuesta a las limitaciones asociadas con esta modalidad migratoria surgió en tiempos de guerra. Sin embargo, el desplazamiento de poblaciones también debe verse como una práctica de guerra para mantener o derrocar el orden establecido en un territorio dado ${ }^{3}$. Entonces, el estudio del desplazamiento forzado lleva a considerar su manifestación tanto desde el punto de vista del uno o individuo (como modalidad migratoria
${ }^{3}$ Las violaciones de la Jus ad bellum abren un margen de maniobra para los actores armados involucradosen los enfrentamientos, lo que da lugar a transiciones en las prácticas violentasy, según una lectura local de la Jus in bello (Rodriguez-Daviaud, 2010). Sobre este tema, véanse también los escritos de Daniel Pécaut.

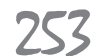


global) como del plural o grupo (como categoría movilizada en los procesos de demandas sociales y negociación institucional solicitados localmente).

\section{La ciudad-refugio a la luz de sus márgenes urbanos: territorios en disputa}

Si el estatuto de desplazado forzado corresponde a una categoría de Estado, el proceso de desplazamiento forzado es un fenómeno dinámico cuyo análisis requiere un enfoque situacional. Por esta razón, estos desalojos forzosos siguen diferentes modelos que responden tanto a lógicas territoriales como geopolíticas: apropiarse de los recursos naturales o de las tierras; asegurarse de la lealtad de una población o crear alianzas; desarrollar sus actividades económicas, particularmente en relación con la narco-cultura; debilitar las bases del enemigo; vigilar, castigar o eliminar a los disidentes; sabotear las infraestructuras, aterrorizar a las poblaciones pero también reclutar a hombres, niños, niñas y mujeres son todas las razones que incitan a los civiles a abandonar sus lugares de residencia. Frente a esta lista no exhaustiva y dadas las dificultades encontradas en el trabajo de campo para acceder a los relatos de desplazados forzados, rápidamente se hizo evidente que era más fácil examinar los efectos de este fenómeno migratorio que inventariar las causas.

Como categoría de análisis político, territarias 40 movimiento de población que se caracteriza por ser operado bajo coacción. Pero como fenómeno migratorio, se manifiesta principalmente por medio de transformaciones espaciales: este es uno de sus principales efectos. Las bases de datos generadas por los organismos gubernamentales responsables de la aplicación de la Ley 387 de 1997 reflejan las trayectorias seguidas por estos migrantes, víctimas de la guerra. Estas diferencian los lugares de los que son expulsados de los que eligen para reasentarse. Así pues, sus declaraciones señalan movimientos migratorios, que se inician principalmente desde las zonas rurales a las urbanas. Durante muchos años, las ciudades colombianas también han sido vistas como zonas de refugio para las víctimas del conflicto armado interno que huían de los enfrentamientos en el campo entre los diversos actores armados involucrados en el conflicto. Sin constituir un éxodo, esta tendencia al exilio tuvo por efecto transformar la apariencia de estas aglomeraciones. Así, según la base de datos del Banco Mundial, en Colombia, 46 de cada 100 habitantes vivían en las ciudades en 1960, frente a 80 en 2017 (La Banque Mondiale, 2017). Estas cifras ilustran la velocidad del proceso de urbanización colombiano, ya que la mayoría de la población había optado por vivir cerca y dentro de las grandes ciudades del país. Sin embargo, si este periodo corresponde a la formación de los principales actores armados involucrados en el conflicto del país, sería inexacto considerar estas transformaciones únicamente 
por causa de la migración desencadenada por el conflicto armado interno. De hecho, deben tenerse en cuenta otros factores socioeconómicos al explicar las variaciones en la distribución espacial de la población de un país. El conflicto impone sus marcas como contexto político. Pero, como en otros países latinoamericanos, el extenso proceso de urbanización de Colombia ha ido acompañado de otros cambios: la inclusión del país en su proceso de transición demográfica y la aceleración de la industrialización de su economía. Así pues, mientras que el primer parámetro condujo a un aumento de la tasa de crecimiento natural, el segundo condujo a un aumento del atractivo de las zonas urbanas, lo que se repercutió en el saldo migratorio neto (Dureau \& Flórez, 1999). Por lo tanto, estos cambios tuvieron un impacto tanto en la tasa de crecimiento de la población colombiana como en su distribución espacial dentro del país.

A partir de los años sesenta, las principales aglomeraciones urbanas del país experimentaron importantes reconfiguraciones. En Bogotá, tras una fase de expansión espacial intensa, se observaron cambios en los tipos de viviendas producidas, que sean formales o informales: frente a la escasez de terrenos, las viviendas de un solo piso fueron abandonándose paulatinamente a favor de la construcción de edificios residenciales multifamiliares. El sistema urbano colombiano y las configuraciones socio-espaciales de las ciudades han sufrido grandes transformaciones en las últimas dos décadas. Sin embargo, según el modelo de segregación espacial fundamental establecido desde la época colonial, los hogares ricos y pobres continuaron ocupando Bogotá Norte y Bogotá Sur, respectivamente. Su distribución en el espacio urbano continuó de acuerdo con el principio de distinción socioeconómica heredado de la conquista, donde "[...] Spanish American cities functioned as both as tools of conquest and symbols of imperial power [...]. Cities of colony and metropole alike were socially stratified and spatially divided according to race, [...], class, profession and other classifications" (Zeiderman, 2013, p. 73), formando ciudades cuyos puntos cardinales reflejan la segregación económica de los ciudadanos que modelan sus espacios.

A partir de los años ochenta, el modelo de urbanización que la capital había registrado dentro de sus límites llegó a los municipios de su periferia, siguiendo globalmente la misma dinámica. Así, a partir de 1990, el asentamiento urbano de Soacha consolidó su fase de densificación, correspondiendo, entre otros factores, a la intensificación de la práctica del desplazamiento forzado de la población por parte de los grupos involucrados en el conflicto armado interno. Este decenio fue marcado por la emergencia de "formas residenciales" urbanas muy contrastadas. Dentro del espacio urbano legal, el Distrito Capital ha visto "proliferar complejos residenciales cerrados y fortificados" (Caldeira, 2000), en zonas periurbanas del norte, sur 
${ }^{4}$ La autora utiliza el plural.

${ }^{5}$ Marcando la frontera entre el Distrito Capital y el departamento de Cundinamarca (figura 2), el poblamiento del sector de los Altos de Cazucá procedió, según dinámicas de invasiones que fueron iniciadas a partir de la década de 1970, ya sea por las comunidades de migrantes, por la de los "pobreshistóricos"o por intermediarios urbanos llamados "urbanizadores piratas”. Los ciudadanos de la Comuna 4 de Soacha vienen de varias regiones del pais: del Tolima, del Huila, del Cauca, de Santander, de los Llanos Orientales, del Metay, más recientemente, del Pacífico, del Caribe, de Antioquia, pero también de Chocóy de Venezuela, para nombrar solo a las comunidades más presentes en el sector al dia de hoy.

\section{territarias 40}

y Occidente, "cuyas características sobresalientes eran las calles cerradas, las rejas, los muros, los sistemas de vigilancia privada y los circuitos electrónicos integrados de monitoreo en garajes y áreas comunes" (Salcedo, 2015, p. 26-27), mientras que en las márgenes de sus periferias se multiplicaban casi únicamente formas residenciales llamadas "informales" o "clandestinas".

Articuladas en torno a los primeros focos de reasentamiento establecidos por migrantes víctimas de la guerra que llegaron a Bogotá en los años cincuenta y setenta (Salcedo, 2015), estas áreas se ubican en zonas no aptas para proyectos inmobiliarios convencionales porque presentan altos riesgos geológicos. Desde los años noventa, este proceso de para-urbanización, también conocido como "dinámica de la colonización urbana” (Naranjo, 2004, p. 281), ha seguido desarrollándose. Como consecuencia de la imposibilidad de que los recién llegados accedan legalmente a la propiedad en la ciudad, participa así en la formación de "otras ciudades" (Alarcón \& Vásquez, 1995, p. 85), cuyo carácter urbano se pone en tela de juicio ante la informalidad de su vivienda. Así, pues, sin ser zonas fuera de la ley, si es que existen tales espacios, estos sectores se presentan como zonas grises, en el sentido en que constituyen:

Espacios - con o sin cercado- de desregulación social, de naturaleza política (autodeterminación, separatismo y santuario) o socio-económica (espacio del crimen, espacios deshumanizados, espacios dessocializados) de tamaño variable $[\ldots]$ dependientes de un Estado soberano cuyas instituciones centrales no logran - por impotencia o abandono- penetrar para afirmar su dominio, que queda en manos de micro autoridades alternativas" (Minassian, 2011, p. 11 $)^{4}$.

A pesar de las limitaciones analíticas de las múltiples formas de expresión presencial del poder institucional estatal contenidas en este, esta definición tiene la ventaja de enfatizar que tales espacios permanecen políticamente estructurados. También son adecuadas para describir el terreno en el que se desarrollaron la mayoría de las encuestas realizadas durante la investigación doctoral: los Altos de Cazucá ${ }^{5}$ (figuras 1 y 2 ).

Figura 1. Enfoque al área metropolitana de Bogotá, Departamento de Cundinamarca

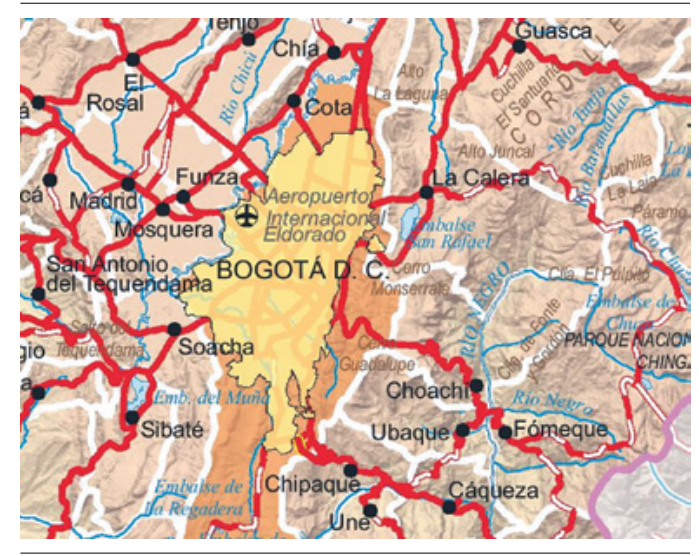

Fuente: IGAC (2012). 
Figura 2. Geolocalización de los Altos de Cazucá y de los Altos de la Florida

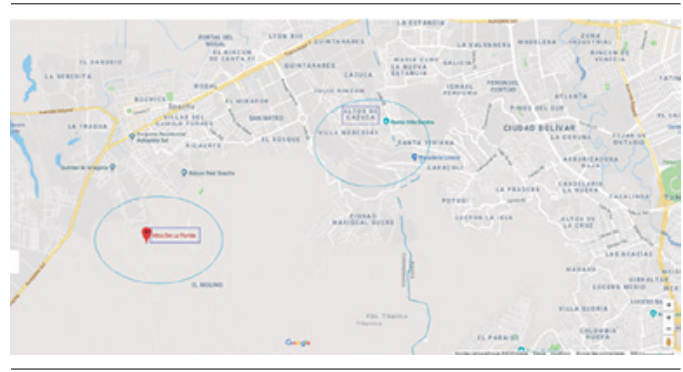

Fuente: elaboración propia con base en Googlemaps. (representación generada el 10/09/2018).

Nota: Las líneas azules representan las fronteras entre Bogotá DC y el Departamento de Cundinamarca. Para mayor visibilidad, se han rodeado los sitios investigados. Vale resaltar que, al contrario de los Altos de Cazucá, los Altos de la Florida no figuran como "barrio". Eso se puede entender teniendo en cuanta su más recién colonización.

Esta zona fue urbanizada de manera informal a partir de finales de los años setenta. Administrativamente ligada a la Comuna 4 de Soacha, municipio al suroeste de Bogotá, actualmente alberga la mayor parte de desplazados forzados en las afueras metropolitanas de Bogotá. En la medida en que los datos disponibles sobre las modalidades urbanas del desplazamiento forzado muestran una práctica que afecta a la mayoría de los ciudadanos que ya se han enfrentado a esta tipología de migración forzada, este sector fue un campo adecuado para las observaciones y entrevistas in situ. Sin embargo, es difícil investigar en esta área. Aparte de que el acceso a la zona se revela complicado, tanto por cuestiones de seguridad, como por razones de transportes, no es fácil establecer sus límites: la gran mayoría de este territorio es el resultado de un proceso de urbanización informal y, como tal, su trazado no corresponde al canon de los edificios urbanos. Por ejemplo, es más probable que los Altos de Cazucá se presenten como un espacio de conurbación en la localidad 19 de Bogotá, Ciudad Bolívar, que como una entidad espacial bajo una administración municipal separada. Este sector en constante expansión es, por tanto, el barrio más meridional de la capital, aunque no integre desde el punto de vista institucional su perímetro urbano.

Resaltar estos elementos puede parecer poco operativo. Sin embargo, esta brecha institucional se encuentra en el centro de la dinámica del desplazamiento forzado intra-urbano que están experimentando estos sectores. Por un lado, hacen compleja la evaluación del fenómeno. Esto se debe a que, en general, el análisis demográfico y espacial no permite contabilizar los movimientos migratorios dentro de una misma entidad territorial administrativa. Por otra parte, el carácter informal del sector lo sitúa al margen de lo que se considera administrativamente como urbano. Este parámetro es en gran medida responsable de la falta de inversión en esta zona de alto riesgo geológico. Aunque disponibles, el agua corriente, la electricidad, las vías de comunicación, pero también el transporte, los centros de salud, la infraestructura educativa y, en general, todo lo relacionado con lo que se entiende bajo el uso del término "espacio urbano" se ha producido en parte de manera informal. Durante las 
${ }^{6}$ Se utiliza el término cartel en su sentido económico más amplio, como "[...] acuerdos implicitos o explicitos - bechos por algunos productores de la misma industria-, a nivel nacional o internacional, para limitar la producción, fijar precios, asignar mercados, determinar ventas, fabricar, cuotas de distribución y compartir ganancias entre los miembrosindividuales" (Delpirou, Mackenzie, 2000, p. 13). Además, no solo bay carteles vinculados a la economía de los narcóticosen las afueras informales de Soacha. Como estasáreas tienen importantes brechas en términos de suministro y servicios (carreteras, policia, salud, alimentos, agua, agua potable, electricidad, gas, etc.), estos sectores económicos deben considerarse mercados de alto potencial. Como resultado, los carteles que cuentan estos barrios luchan o cooperan, según las situaciones, para asegurarse el monopolio de los recursosgenerados por la distribución de estos "servicios básicos" hacia los habitantes de estas zonas marginalizadas.

\section{territarias 40}

investigaciones de terreno, estos elementos fueron objeto de una administración híbrida asumida tanto por el Estado como por diversos actores que operan en el sector la Isla, ubicado en la frontera entre el Distrito Capital y el municipio de Soacha.

Ya sean grupos armados que integran el conflicto, grupos de delincuencia juvenil, carteles que operan en el campo del aprovisionamiento urbano o narco-economía ${ }^{6}$, pero también organizaciones no gubernamentales, estatales o religiosas, la intervención diaria de estos grupos alimenta los fenómenos de competencia y colaboración existentes entre los habitantes de Cazucá. De hecho, aunque no correspondan con la representación convencional de lo urbano por no haber sido urbanizado según las normas de planeación del territorio, el control de este sector es disputado, porque ofrece muchos recursos materiales. Por un lado, este espacio informal tiene la gran ventaja de permitir el acceso a viviendas de bajo costo sin los imperativos que ello implica (garantías, renta fija, aportes iniciales de capital). Por otra parte, el poder adquisitivo de los hogares aumenta debido al carácter informal de los mercados del sector. Por último, hacerse propietario o inquilino no significa estar aislado del "área urbana continua" (Dureau, Lulle, Souchaud, Contreras, 2014, p. 90-91), al contrario. En la medida en que esta comuna colinda con la localidad 19 de Bogotá, la elección de residencia en los Altos de Cazucá permite a los hogares mantener una proximidad geográfica a la ciudad formal, ya que existe una carretera que une el barrio Sierra Morena III Sector de Bogotá con el barrio La Isla de Soacha. Esta articulación es un prerrequisito esencial para su vida cotidiana: les abre acceso a los centros administrativos de la capital, pero también a su mercado laboral. Por lo tanto, esta ubicación geográfica es una ventaja importante: dadas las múltiples posibilidades de transporte, empleo y acceso a los servicios públicos (Hannerz, 1983, p. 137), la economía de este sector sigue siendo asequible para un gran número de personas.

Por todas estas razones, la vivienda y los terrenos en los Altos de Cazucá son valorados por las poblaciones económicamente desfavorecidas de la aglomeración de Bogotá. Por ejemplo, la elección de la residencia en el área loma fue descrita a menudo de manera positiva por los residentes, especialmente aquellos que habían experimentado el desplazamiento forzado. De hecho, una vez que se ha dado este paso, muchos esperan un retorno a una situación estable, contrariamente a "las experiencias de la 'vida móvil' (Stepputat, et al., 1998), en la que la memoria de los acontecimientos traumáticos se mezcla con la búsqueda de mejores condiciones de vida" (Meertens, 2001, p. 120), que caracterizan los relatos de sus viajes. Sin embargo, esta instalación solo se considera temporal, ya que, de hecho, si existe, no tiene valor legal y está fuera de la ley. Además, este espacio también recoge las dinámicas de desalojo que han seguido creciendo en los 
últimos quince años, como lo demuestra el informe publicado por CODHES en abril de $2013^{7}$. Este fenómeno está directamente relacionado con la informalidad que caracteriza los mercados de este sector, ya sean terrenos, negocios, alimentos, energía o recreativos. La Comuna de Altos de Cazucá tiene una numerosa población. Según el Departamento Administrativo Nacional de Estadísticas (DANE), en el año 2005, ascendió a 63245 ciudadanos de los 455992 que cuenta el municipio, de los cuales casi 8000 se encontraban en desplazamiento forzado (Pinzón, 2007, p. 273). A pesar de su precariedad, el peso económico que representan estos hogares es por lo tanto importante y fácil de entender. Por una parte, existe un gran interés al controlar unos de los mercados o servicios básicos que necesitan. Por otro lado, el carácter informal de sus viviendas facilita tanto el desarrollo de actividades ilegales como la construcción de sistema de vacunas multipolares.

Ya sea directa o indirectamente, los habitantes de Cazucá constituyen una importante ganancia financiera inesperada para los muchos "titulares de oficios" que forman el sistema de ordenación de la Comuna 4. Como "personas sociales que ocupan posiciones de poder" (Leach, 1972, p. 31), no operan en las mismas áreas de la vida social y ordenan una violencia que puede dividirse en varias categorías: física, económica, cultural, pero también simbólica. Aunque anormales y a veces contradictorias, sus reglas rigen conjuntamente las áreas informales de Soacha. Como tales, todos estos "titulares de oficios" (Leach, 1972 ) se presentan como garantes del orden social cotidiano. Así, a pesar de la aparente ambigüedad que tal situación revela, en estos espacios coexisten simultáneamente $\mathrm{ONG}$, OING, milicias privadas, grupos armados ilegales, pandillas de delincuencia juvenil, sicarios, carteles, instituciones gubernamentales, asociaciones de vecinos, pero también personal policial y militar. En la medida en que comparten los mercados (Duriez, 2014), el orden establecido por el efecto recíproco de sus acciones en el sector (Gluckman, 1958) se basa en la importante vulnerabilidad material y simbólica en la que se halla la población cazuqueña. Sin embargo, este sistema de control no se aplica directamente a los habitantes: es una función del territorio que ocupan y es el control de este espacio lo que se disputan los "titulares de cargos".

Los intereses económicos que encierran los márgenes urbanos son potenciales en el sentido en que "existen en potencia, virtualmente" (TLFI, potencial, I-A). A los "titulares de oficios" que operan en los Altos de Cazucá les interesa mantener esta franja urbana informal, pues en el caso contrario, estos mercados ya no existirían. Su integración en el perímetro urbano formal daría lugar al desarrollo de infraestructuras colectivas. Desde esta perspectiva, el mantenimiento de los sistemas de orden que gobiernan la vida cotidiana de esta Comuna depende de su aparente inestabilidad. Por eso, los grupos de actores que están
Publicado tres años después del inicio de la investigación, este documento contiene una parte reservada exclusivamente para el caso Soachuno, revelando que, si bien este es el sitio más importante del departamento de Cundinamarca en términos de recibir desplazados, también es el que más expulsa. Sin embargo, al presentar estos resultados, los autores del informe destacan la importante parte de la sub-evaluación que actualmente se está llevando a cabo en el estudio de la modalidad intra-urbana del desplazamiento forzado.

territarias 40 
8 Tal como Putumayo, el Caribe, Santander, el Pacifico, Antioquia, Caldaso Meta para citar las que más se ven dentro de la organización socio espacial de los barrios que conformaban los Altos de Cazucá en el momento de nuestra investigación.

\section{territarias 40}

allí, no solo compiten por el control de un territorio marginado. Por medio de sus acciones, pretenden mantener este hábitat en un "sistema de equilibrio" variable (Leach, 1972). Esta realidad social puede parecer contradictoria. Sin embargo, es esencial entender la vida cotidiana de estos barrios que, aunque siguen siendo informales, son codiciados. En efecto, constituyen una alternativa inmobiliaria que, si no envidiable y sostenible, es accesible.

\section{Desplazamiento forzado intra- urbano, entre la transposición y la transferencia de una práctica migratoria históricamente vinculada con la guerra}

Los actores armados al margen de la ley presentes en los Altos de Cazucá representan una parte importante de los titulares de cargos del sector. Siendo múltiples, ejercen influencia en la Comuna desde varios micro-territorios con fronteras cambiantes. Para fundamentar su legitimidad de acción, estos grupos se basan en las deficiencias de "universalización y estandarización del Estado a nivel internacional" (Minassian, 2011 , p. 18). Se colocan así en una relación de oposición al orden estatal, siendo aquella tanto "estatocéntrica" como este. La oposición también opera en el ámbito socioeconómico. De hecho, los actores se oponen a la aplicación del modelo político, pero no a su sistema, así como se oponen al modelo de redistribución económica pero no a su existencia (Minassian, 2011). De hecho, en la medida en que su modus operandi es una aplicación de ambos modelos y que depende totalmente de su existencia, no ponen en tela de juicio el sistema económico mundial. Su legitimidad de acción se basa en la gestión política de las zonas grises como territorios de exclusión. Así, para que su presencia sea tolerada por los habitantes y para que sus acciones puedan funcionar plenamente, estos colectivos ofrecen sus servicios, presentándolos como soluciones económicas que, sin ser ni fiables ni sostenibles, se muestran como recursos estables y diversificados.

El despliegue de sus acciones se basa en una experiencia común que, en el contexto colombiano, procede de la experiencia política y económica del conflicto armado interno. La mayoría de los ciudadanos que vinieron a instalarse en los Altos de Cazucá no comparten la misma cultura o experiencia del poder estatal. Procediendo de diferentes regiones de Colombia $^{8}$, organizaron su asentamiento en la Comuna operando por agrupación regional, con el objetivo de mantener una organización social lo más análoga posible a su vida de antes (Duriez, 2014). Sin embargo, a pesar de estas distinciones, todos comparten la experiencia del conflicto interno. Las acciones desarrolladas por los grupos armados giran en torno a esta experiencia. Adoptar esta estrategia les permite situar sus prácticas violentas en una continuidad memorial, compartida por todos los habitantes de la zona. Su presencia y acciones actúan como una 
referencia compartida para los habitantes. Los grupos armados al margen de la ley se convierten en posibles interlocutores en la socialización de la población del sector, porque "si cualquier acción recíproca entre los hombres es una socialización, entonces el conflicto, que es una de las más activas, y que lógicamente es imposible reducir a un solo elemento, debe ser considerado absolutamente como una socialización" (Simmel, 2010, p. 265).

Así, estos grupos no solo se presentan como agentes que participan en la violencia física que empapa la ciudad-bis, sino que también son actores identificados como integradores de sistemas de intercambio. Esta situación puede parecer ambigua. Sin embargo, frente a un conflicto prolongado, “[...] es casi inevitable que un elemento relacional común quede entrelazado con la hostilidad tan pronto como la etapa de violencia abierta haya dado paso a cualquier otra relación, o cuando el grado de hostilidad entre las partes quizá siga igual" (Simmel, 2010, p. 275). En este contexto, operan tanto por cuenta propia como a petición de terceros. Algunas zonas periurbanas informales de las principales ciudades colombianas han registrado la llegada de los llamados grupos armados subversivos a petición de sus residentes (Naranjo, 2004) desde la década de $1980^{9}$. Sin embargo, recurrir a su intervención no fue una respuesta a la existencia de fenómenos violentos, sino más bien porque se practicaba la violencia contra la comunidad de residentes de estos sectores, lo que perjudicaba los vínculos sociales (Angarita, Jiménez, Gallo et al., 2007). Hicieron un llamamiento a estos grupos para que mantuvieran el orden en la vecindad: el objetivo era preservar su forma de vida. Sin embargo, los términos que gobiernan estos acuerdos, cuyo propósito era reformar a los delincuentes, fueron rápidamente salvados: la represión finalmente se aplicó a todos los habitantes de las áreas periurbanas informales.

La práctica del desplazamiento forzado dentro de las ciudades es una de las técnicas coercitivas más eficaces empleadas por estos detentores de cargos. Este método de desahucio es coercitivo, como los que se observan en el campo, ya que no deja otra opción a las víctimas sino abandonar los lugares de residencia, aparte de los grandes esfuerzos realizados para ocultar la urgencia de esta partida. En todo caso, va acompañada pues de un sentimiento de abandono y da paso a la duda permanente, ya sea para los que se van o para los que permanecen: ‘adónde se fueron? ¿Qué ha pasado? Es eficaz, porque como práctica afiliada al conflicto armado interno, esta estrategia es entendida por todos los habitantes del sector. La mera probabilidad de su aplicación multiplica por diez el poder de control de los grupos armados al margen de la ley y refuerza su dominio del territorio, el cual se entiende aquí como lugar de producción y reproducción de lo social. Porque:

¿qué está en juego en la reivindicación y el control de un territorio? La garantía de un
9 No hay evidencia que sugiere que esta situación ocurrió en los Altos de Cazucá, pero si para los habitantes de la Comuna 13 de Medellín, como se señaló en la obra de Angarita, Jiménez, Gallo et al., (2007, p.124-126) 
acceso social y material permanente a un conjunto de recursos naturales que puedan garantizar, en gran medida, la continuidad material del grupo local [...]. En otras palabras, la prioridad es reclamar para sí mismo la propiedad de una parte de la naturaleza (Godelier, 2010, 107-108).

Se desprende de ello que la práctica del desplazamiento forzado de la población en las zonas urbanas constituye una transposición, en el sentido de adaptación, de las lógicas de los conflictos armados en las ciudades. Demostrando que son capaces de ejercer el poder de vida y muerte sobre la gente en las áreas urbanas informales, aseguran su colaboración si no consiguen ganar lealtad, como suele ocurrir en las áreas rurales donde "los que ordenan deben ser obedecidos y tienen armas" (Noël, 2012). De hecho, los grupos armados al margen de la ley están históricamente ligados a la constitución positiva (orden) y negativa (desplazamiento) de las áreas periurbanas informales: están tan incluidos como excluidos de su espacio político, admitiendo este último como una dimensión tanto física como memorial (Lefebvre, 1974). Para fundamentar sus acciones y ampliar su alcance, se basan en la violencia simbólica que atraviesa los márgenes informales y presenta sus prácticas como un poder de exclusión inclusiva. En la medida en que sus servicios están abiertos a todos los residentes mediante pago, pueden ser contratados para desalojar a un vecino indeseado territarias 40 o una familia que ocupe una parcela de tierra, pero también por venganza. Este fue el caso de Mauricio, quien me contó su desplazamiento forzado, mientras esperaba en las instalaciones de la Casa de los Derechos para solicitar información sobre una solicitud administrativa:

“¿Es que yo [...] yo soy desmovilizado, si me entiende? [...] Llevo dos años acá, en esta comuna. Llegué hace dos años acá, porque no podía irme a otro lugar [...] Afuera, los inquilinatos son muy costosos y no se puede pagarlos con el subsidio que nos da el gobierno $[\ldots]$ Y es que $[\ldots]$ cuando rendimos las armas, eso fue $[\ldots]$ pues como si hubiéramos traicionado a nuestros compañeros. Entonces cuando supieron que yo vivía en el barrio, pues me cayeron de una a vengarse [...] llegaron al anochecer. Mi esposa estaba afuera, frente a la casa y dos tipos llegaron en moto, en el barrio $x$ y pues [...] la dispararon gritando que "saludos del bloque", frente a mi... Esta noche, fui a declarar el asesinato de mi esposa al CAI, y cuando me devolví, habían quemado mi casa [...] Entonces me marché del barrio [...] Fui a otro lugar, en Soacha, pero a otro barrio [...]. No puedo más quedarme por acá $[. .$.$] Por eso estoy en$ esto de pedir un subsidio al gobierno. Quiero regresarme al campo, a criar marranos y cuidar mis hijos. Quiero que estén en un lugar seguro [...] Acá, es peligroso y nadie quiere darme trabajo, pero los marranos, sé cómo criarlos $[\ldots]$ es lo que yo hacía antes de pues $[\ldots]$ antes de enrolarme en las filas [...] con mi papá y mis hermanos, teníamos un ganado de marranos (Mauricio, 2012). 
Habiendo dejado Cazucá después de presenciar el asesinato de su esposa y viendo su casa incendiada por el Bloque que había dejado, Mauricio "se mudó a otro lugar, aún en Soacha, pero a otra parte". Sin embargo, como muchos residentes de la Comuna 4, quería irse porque "aquí no es seguro" y "nadie quiere darle un trabajo". La experiencia de Mauricio resalta así dos elementos importantes en relación con el desplazamiento forzado intra-urbano. En primer lugar, esta práctica del exilio no solo apunta a desplazados, sino también a cualquier persona y/o hogar que se encuentre en un área donde el control es disputado por grupos armados fuera de la ley. En segundo lugar, los patrocinadores de las sentencias generalmente no las ejecutarán ellos mismos. Ya sea una cuestión de desplazamiento o de homicidio extrajudicial, prefieren contratar a agentes para entregar un mensaje suyo. El relato de Mauricio confirma así la vigencia de un fenómeno de pandilla múltiple, particularmente marcado en las zonas urbanas informales. Esta dinámica hace más compleja la categorización del desalojo forzoso en desplazamiento forzado; en parte explica la infra-evaluación de las modalidades urbanas del desplazamiento forzado, cuyo análisis actual aún se centra en las causas de salida, y no en sus efectos. Sin embargo, la perspectiva se invierte a medida que el análisis se centra en los efectos de esta modalidad de movilidad forzada. Los desplazamientos forzados operados en zonas urbanas tienen muchas similitudes con los operados en zonas rurales. Situada a medio camino entre la expulsión forzada de un enemigo interno en movimiento y el desalojo armado de una población considerada indeseable, su práctica forma parte de la lógica política y estratégica. Por ejemplo, los relatos recopilados durante la investigación de terreno, a menudo se referían a una técnica para corregir conductas desviadas o para detener actividades que perturbaban el orden social establecido. Según Esperanza, madre de tres hijos que había sufrido cuatro desplazamientos forzados, entre los cuales dos en zonas urbanas, las razones de su desalojo se debieron a su participación en el trabajo social con madres lactantes y desplazadas de la zona. En el momento de la investigación, se acababa de trasladar a Cazucá con su familia en un anonimato total, lo que significó abandonar su participación en este proyecto apoyado por la UNICEF y la OMS. Fue también el análisis de Pablo, un dirigente campesino santandereano adscrito a la Unión Patriótica y que se trasladó por primera vez a Soacha, en el barrio Julio Rincón, en los años ochenta. Habiendo sufrido cuatro ataques, ha obtenido el estatuto de refugiado, pero ha optado por volver a Colombia en el momento de la investigación para "continuar su lucha" con los miembros de la Unión, dentro del proyecto social agrícola que dirige en el sector. Como tal, no vivía en el barrio la Isla, sino que solía ir diariamente. Finalmente, la práctica de desplazamientos forzado en las zonas urbanas también permite desplazar a quienes se convierten 
en una amenaza para los actores armados que ofician en barrios, como fue el caso de José, un adolescente de 13 años que presenció una ejecución extrajudicial en el momento de la investigación.

Los casos presentados ilustran así que el uso de los desalojos forzosos en las zonas urbanas cumple funciones punitivas. Ya sea para Esperanza, Pablo o José, su desplazamiento forzado tuvo lugar tras la transgresión de una regla dóxica. Como resultado, estas prácticas, a menudo, fueron presentadas como formando parte de un castigo. Los discursos pronunciados en torno a ello justificaban su advenimiento sobre la base de un principio de merecerlo, derivado de la posición social o de la carrera relacional de los interesados. Así, como decía Fernanda, madre de tres niños que había sufrido dos desplazamientos forzados, le parecía normal mover a los que eran "malos con sus vecinos", o al menos "lo entendía", tomando en cuenta el sector. Sin embargo, a ella le parecía "horrible" y rogó al Señor que no le pasara lo mismo. Así, cuando las causas que provocan estos desalojos forzosos se perciben como endógenas a las trayectorias de los que los sufren, el desplazamiento se vuelve normal o incluso habitual. Sin embargo, cuando son provocadas por fuerzas exógenas, especialmente cuando se utiliza el panfleto, y como fue el caso del desplazamiento masivo intra-urbano, que tuvo lugar en enero de 2012 en los Altos de la Florida, la Comuna 6 de Soacha, estas experiencias se vuelven terribles e irracionales.
De hecho, ¿qué sentido tiene alejar a la población de un sector cuyo peso económico depende enteramente de la informalidad de su actividad humana? La respuesta a esta pregunta se encuentra en el vínculo entre esta práctica y la conducta del conflicto armado interno. Una de las razones más comunes dadas por el interés en desplazar a la población rural en Colombia es la cuestión del uso de la tierra. Al expulsar a los terratenientes que se resistían a sus actividades, los grupos armados implicados en el conflicto interno pudieron acumular grandes extensiones de tierra cultivable. Las tierras así abandonadas o despojadas podrían ser vendidas a empresas o particulares, pero también explotadas en la narcoeconomía. En el caso de desplazamientos forzados que operan en áreas urbanas, los territorios en cuestión se ubican en márgenes donde "el Estado destaca por su ausencia" (Soacha, funcionario, 2012). Estos territorios, densamente poblados, representan una alternativa residencial a la creciente escasez de solares en el área metropolitana de Bogotá. Pero mientras el número de habitantes sigue creciendo, la superficie tiende a alcanzar sus límites. Además, estos sectores están sujetos al desarrollo de un importante mercado paralegal de tierras.

En la medida en que existe una abundancia de solicitudes para adquirir un terreno en el cinturón de pobreza soachuno, el mercado de la vivienda tiende a ser el sector de actividad más rentable para los grupos armados al margen de la ley. 
Además, algunos, como los Terreros de Altos de la Florida se han especializado en su gestión y control, como lo atestigua un alto funcionario de una ONGI que trabaja en este sector:

Estamos observando una situación adicional [...] Es una dinámica de violencia, digamos, un poco más compleja, y es como un mapa de actores que confluyen en la misma área [...] y hay unos, los que llaman ellos terreros, que son, que vienen de "Tierra". ¿Cierto? Y es por la situación de legalidad de la tierra de Altos de la Florida. Altos de la Florida es una zona de invasión que pertenece a unos, a unas personas naturales que son... (silencios) a unos privados [...] Entonces hay un conflicto entre la comunidad y los propietarios de estas tierras. Dicen que detrás de eso hay unas mafias que manejan la propiedad de la tierra. Entonces lo que hacen es venderle el, el uso, digamos, del terreno, porque no es la propiedad porque no lo pueden hacer, porque no es de ellos, el uso de algunos terrenos a la gente que recién llega. Y lo que están haciendo con el desplazamiento aliado con estas bandas juveniles y con los actores armados es provocar un nuevo desplazamiento de la población que está ahí para poder venderla nuevamente. ¿Si me explico? [...] No hay pruebas, pues nosotros no encontramos una constancia que nos permite verificar que, en efecto, hay una relación entre las bandas juveniles y los actores armados y las mafias de los terreros... Pero sí hay algunos indicios, muy claros, que nos pueden inducir a ver esta relación [...] hubo una situación en la que la policía, a raíz precisamente del desplazamiento de la población afro-colombiana, la policía y la fuerza pública se tomaron la zona, realizaron muchas operaciones, y a través de estas operaciones de inteligencia realizaron unas capturas. Y entre esas capturas que hicieron, cogieron a los autores del desplazamiento, los cuales hacen parte de estas bandas juveniles. El hecho es que al final del proceso judicial, a unos de los menores de edad es el que incumplan $[\ldots] \mathrm{Y}$ a ese menor de edad le ponen, le pagan un avocado defensor. A través de informaciones de otras entidades, pudimos ver que este avocado defensor $[. .$. es pagado por el señor que la comunidad reconoce como el que maneja esta mafia. ¿Sí me explico? ¿Si entiendes un poco como es este mapa de relación? Entonces eso nos lleva a decir que, en efecto, sí hay una relación entre estas mafias y las bandas juveniles, que ellos movilizan recursos para defenderlos cuando los contratan a sacar la gente del barrio y así tener esas casas libres, para poderlas revenderlas. ¿Sí me explico?” (Funcionario ONGI, 2012).

Este extracto de la entrevista enfatiza que estos márgenes urbanos no solo son disputados con el fin de establecer un control social postmigratorio, sino también con fines económicos. Esta nueva situación enmarca el espacio dentro de una dinámica de violencia más compleja que la que se observa en el campo, ya que los actores armados son más numerosos y están más dispuestos a enfrentarse entre sí 
para converger hacia este espacio de importancia estratégica. Si bien, algunas de sus actividades están en relación con la dinámica económica identificada en el campo, especialmente por medio del micro-tráfico de estupefacientes y el tráfico de armas, otras se han desarrollado precisamente en torno al fenómeno del desplazamiento forzado, como lo evidencian las actividades de los terreros. Reclutada por el sector privado que posee el título de propiedad de la tierra en los Altos de la Florida, esta mafia regula un conflicto que, si bien ha sido visible durante una década en las zonas urbanas, está en el corazón de los enfrentamientos armados en este país: el del orden y distribución de la tierra. Desde esta perspectiva, los desplazamientos forzados operados en áreas urbanizadas constituyen técnicas de regulación cuyo propósito es asegurar, para el grupo iniciador, el control territorial, un proceso que se materializa en el pago de sobornos o en desalojos forzosos bajo amenaza de muerte. Los terreros actúan para los privados que detentan las escrituras notariales de este territorio de Soacha. Operan en pandillas y tienen recursos y redes sustanciales para sofocar las pruebas de sus acciones. La práctica de estos desalojos forzosos solo es visible cuando tiene un impacto masivo en una comunidad, como ocurrió en enero de 2012. Sin embargo, no se trata de un fenómeno ocasional. Durante los estudios de terreno, la Defensoría del Pueblo estimó que, en promedio, siete unidades familiares se vieron obligadas a abandonar los Altos de Cazucá cada semana, proceso dinámico que también se observó en los Altos de la Florida, como lo contó un miembro de una asociación que trabajó durante más de diez años en esta Comuna:

No es una cosa puntual. Eso es el resultado de hechos, que vinieron sucediendo $[\ldots]$ digamos que es una correlación de hechos... hace dos años, más o menos... más... dos años y medio, tres [...] Estamos viviendo en los Altos de la Florida una situación muy complicada, tremendamente complicada [...] Entonces, eeeh... bueno eso ha sido muy fuerte, pero sí queda claro que fueron expulsando estas familias... esto se volvió invivible, no tengo el número exacto pero llevamos sesenta familias desplazadas, del barrio hacia afuera, hacia Soacha, hacia Bogotá... es decir intra-urbano [...] Yo creo que desde el momento veo más gente por fuera que dentro del barrio (sonríe). Algunas de estas familias llegan a mi casa, que está fuera de la Florida, a preguntarme si la situación ya está más tranquila... Para saber si pueden devolverse... Y, de hecho, algunas de ellas ya lo hicieron. Se devolvieron a sus casas, y aquí están, pero mantienen perfil bajo (Miembro de asociación, 2012).

Este extracto de entrevista ilustra el vínculo entre la práctica del desplazamiento forzado en las zonas urbanas y la violencia difusa que impregna los barrios informales. Frente a "situaciones muy complicadas", los habitantes de estos barrios son conscientes de que, aunque recientemente se 
han hecho visibles, "esta dinámica no es algo puntual". Así pues, cuando se enfrentan a ella, las familias tienden a desplazarse "dentro de las ciudades o entre las ciudades". Sin embargo, no suspenden sus relaciones interpersonales: las mantienen fuera del barrio para saber si "pueden volver". Algunos incluso "se reinstalan en sus casas" a pesar de las amenazas, adoptando un "perfil bajo" para neutralizarlas lo más posible. Asimismo, la práctica de desplazamientos forzados en áreas urbanas, no es solo una transferencia léxica cuyo uso apuntaría a asentar la dominación de los grupos armados al margen de la ley»

en los territorios informales de los soachunos. Se está frente a la transposición de una técnica organizada que responde a lógicas de tenencia de la tierra similares a las que animan los desalojos de civiles en el campo. La única diferencia está en el territorio donde se practican. De este modo, cuando se realizan dentro o entre las ciudades, las trayectorias seguidas por esta modalidad de movilidad bajo coacciones testimonian de una estrategia de conservación: las víctimas de estas prácticas permanecen en el espacio urbano, porque desean preservar su forma de vida.

\section{Conclusiones}

Las expulsiones forzosas llevadas a cabo en zonas urbanas se revelan en territorios cuyo significado cultural es distinto del de un estilo de vida rural. Sin embargo, estas migraciones se expresan recurriendo al mismo significante lingüístico: el de desplazamiento forzado. Esta distinción espacial "[...] no debería invitarnos a observar de manera fragmentaria o fragmentada" el desarrollo de estos movimientos. Esta “[...] diversidad [...] depende menos del aislamiento de los grupos" comprometidos en estos flujos migratorios "[...] que de las relaciones que los unen" (Lévi-Strauss, 2001, p. 42 ). Esta es la razón por la que los estudios realizados sobre las formas urbanas de esta modalidad de movilidad bajo coacción consideran que se está ante una práctica bélica afiliada a la descrita por la categoría jurídica de desplazamiento forzado, asumiendo que:

Según el marco normativo y la jurisprudencia legislativa, el desplazamiento forzado intra-urbano debe entenderse como una nueva tipología de desplazamiento forzado interna. Esta definición implica entender el fenómeno como una realidad en sí compleja, sometida a los cambios y que se impone infringiendo continuamente los derechos humanos de las personas víctimas, y eso, tanto por la presión de los grupos armados como por la ineficacia de las autoridades encargadas de garantizar la prevención, la protección y el cuidado de la población víctima de las migraciones forzadas en el interior de las ciudades" (Atehortúa, 2009, p. 253) (CODHES, 2013, p. 39).

Como categoría migratoria, el análisis de los datos estadísticos disponibles sobre el desplazamiento forzado intra-urbano 
revela que su práctica no es aleatoria. Afecta principalmente a las denominadas personas vulnerables que viven "fuera de los lugares”»(Agier, 2009). La causa estructural de estas migraciones radica en la exclusión social de la que padecen los espacios que registran estas dinámicas. Esta observación invita a observar el lugar que estos territorios ocupan a nivel de ciudad, pero también a estudiar su organización interna a la luz de la historia de su formación; en este contexto, la experiencia del conflicto armado interno ocupa un lugar preponderante. En efecto, ya sea por razones estratégicas o económicas, la práctica de los desplazamientos forzados de población siempre ha acompañado los combates, $\mathrm{y}$, si bien, es cierto que las zonas urbanas no se prestan a los mismos procesos productivos que las zonas agrícolas, sí presentan muchos recursos para los actores armados del país. La gran mayoría de ellos son producidos por ciudadanos que vinieron a vivir en la ciudad en tiempos de guerra: algunos lo han hecho para encontrar oportunidades, otros para buscar refugio. El conflicto armado interno ha tenido un impacto en la dinámica urbana de las ciudades colombianas durante la segunda mitad del siglo $\mathrm{Xx}$, aunque solo sea como contexto político.

Así, el análisis de los modelos residenciales urbanos ilustra en parte los efectos de la situación armada sobre los patrones de "modelización urbana" que siguieron los municipios colombianos. Estos espacios proporcionan valiosa información sobre los vínculos entre territorio y guerra a la luz de las diferentes dinámicas migratorias que han surgido tras los conflictos que han animado la lucha. Aunque múltiples, estos espacios urbanos pueden dividirse esquemáticamente en dos categorías. Por un lado, hay una ciudad "formal", la de los habitantes urbanos que ocupan los espacios catastrales de los municipios y, por otro lado, una ciudad informal, que surgió bajo el impulso de los "forjadores de ciudades" (Salcedo, 2015). Desde su formación, estas “ciudades-bis" (Agier, 1999, pp. 7-8) se han presentado como alternativas residenciales a la vivienda convencional. Pero las alternativas no significan anarquía, aunque así se representan todavía. Como espacios, estos territorios urbanos son ocupados y organizados por las comunidades que los habitan. Los datos presentados en este artículo son el resultado de observaciones y entrevistas realizadas en los Altos de Cazucá y en los Altos de la Florida. Si bien, el propósito de la encuesta fue dar cuenta de los vínculos entre el conflicto armado interno y la práctica de desplazamientos forzados en las áreas urbanas, la investigación se ha enfocado en la importancia de la gestión política de la tierra en el desarrollo de estos fenómenos migratorios. De hecho, la historia de la formación de estos barrios no habla directamente de las dinámicas residenciales que los estructuran. Sin embargo, revela los vínculos entre su formación y las dinámicas armadas del conflicto interno. El enfoque territorial permite identificar las lógicas organizativas de estos espacios. 
Como territorios, las formas de vivir y ordenar la vida cotidiana responden a una lógica de producción y de reproducción del social. Como tal, los desplazamientos forzados que allí se realizan integran una dimensión tanto material como simbólica. Simbólica, por un lado, porque su práctica, que es conocida por todos los habitantes, tiene una dimensión ritual. A pesar de las variaciones en sus métodos de funcionamiento, la repetición de este fenómeno justifica tanto el uso de múltiples "detentores de cargos" como su presencia en estos sectores. Estas dimensiones se relacionan con la "esencia del fenómeno" tal como se percibe cuando se practica en las zonas rurales y "encajan muy bien con un incesante movimiento de emergencia, resurgimiento y, sobre todo, metamorfosis" en el sentido en que "el ámbito del ritual nunca queda establecido" (Fabre, 1987 , p. 3-4). Material, por otro lado, porque como modalidad de movilidad bajo coacción, también existe un interés económico en desplazar a la población que ha optado por vivir en estos sectores: estos desalojos participan en una lógica paralegal de especulación territorial similar a la que anima la práctica del desplazamiento forzado en las zonas rurales. Así pues, el estudio de este fenómeno invita a "tener en cuenta no solo los cambios en la posición de los individuos en relación con un sistema ideal de relaciones de status, sino también los cambios en el propio sistema ideal, es decir, los cambios en la estructura del poder" (Lévi-Strauss, 2001 [1971], p. 42 ) inducidos por el cambio de territorio.

\section{Referencias}

Abélès, M. (2008). Anthropologie de la globalisation. Paris: Payot.

ACNUR/UNHCR (2018). Tendencias globales. Desplazamiento forzado en 2017. UNHCR. Recuperado de http://www. acnur.org/5b2956a04.pdf

Agamben, G. (2003). Etat d'exception. vol. 1, trad. Joël Gayraud. Paris: Éditions du Seuil.

Agier, M. (2009). Incertitude urbaine et liminarité rituelle. Anthropologie des hors-lieux. Zainak. Cuadernos de Antropología-Etnografía, 31, 251-232.

Agier, M. (2005). Le son de la guerre. Politix, 69, 83-99.

Agier, M. (2000). Perte de lieux, dénuement et urbanisation: les desplazados de Colombie. Autrepart, 14, 91-106.

Agier, M. (1999). L'invention de la ville: banlieues, townships, invasions et favelas. Paris: Archives Contemporaines.

Alarcón, U. M. V., \& Vásquez, T. (1995). Enterrar y callar: las masacres en Colombia, 1980-1993. vol. 1, Bogotá: Comité Permanente por la Defensa de los Derechos Humanos-Fundación Terres des Hommes.

Albarracín, M. N. (2004). Desplazamiento forzado. Dinámicas de guerra, exclusión $y$ desarraigo. Bogotá: Universidad Nacional de Colombia-ACNUR.

Angarita, C. P. E., Gallo, H., Jiménez, Z. B. I., Atehortúa, A. C. I., Londoño, B. H. L., Sánchez, L. A. et al. (2007). Dinámicas de guerra y construcción de

territarias 40 269

EL DESPLAZAMIENTO FORZADO INTRAURBANO: UNA MODALIDAD DE MOVILIDAD RESIDENCIAL 


\section{territarias 40}

paz. Estudios interdisciplinarios armados en la Comuna 13 de Medellín. Medellín: Corporación REGIÓN.

Caldeira, T. (2007). Ciudad de Muros. [trad. C. Solans]. Barcelona: Editorial Gedisa.

Clausewitz, K. (1995). De la guerre, trad. Laurent Murawiec. Paris: Perrin.

Consultoría para los derechos humanos y el desplazamiento (CODHES) (2013). Desplazamiento forzado intra-urbano y soluciones duraderas. Una aproximación desde los casos de Buenaventura, Tumaco y Soacha. Bogotá: CODHES-ACNUR.

Corten, A., \& Côté, E. (2008). La violence dans l'imaginaire latino-américain. Québec: Presses Universitaires du Québec.

Daviaud, S. (2010). L'enjeu des droits de l'homme dans le conflit colombien. Paris: Karthala.

Delpirou, A., Mackenzie, E. (2000). Les cartels criminels cocaine et héroïne, une industrie lourde en Amérique latine. Paris: Presses universitaires de France. Dureau F., Lulle T., Souchaud S., \& Contreras Y. (2015). Movilidades y cambio urbano: Bogotá, Santiago y São Paulo. Bogotá: Universidad Externado de Colombia.

Dureau, F., Barbary, O., \& Gouëset, V. (coord.) (2007). Ciudades y sociedades en mutación: lecturas cruzadas sobre Colombia. Bogotá: Universidad Externado de Colombia.

Dureau, F., \& Flórez C. E. (1996). Dinámicas demográficas colombianas: de lo nacional a lo local. Documento CEDE, 96-01, 50 .
Duriez, T. (2014). Les déplacements forcés intra-urbains dans les comunas 4 et 6 de Soacha (Colombie): entre violences urbains et urbanisation de la guerre. Enquête ethnologique d'une mobilité sous contrainte politisée. Tesis de doctorado en Arqueología, Etnología, Prehistoria. Niza: Université Nice Sophia Antipolis. Fabre, D. (1987). Le rite et ses raisons. Terrain, 8, 3-7.

Gluckman, M. (1958). Analysis of a social situation in modern Zululand. Manchester: The Rhodes-Livingstone Institute, Manchester University Press.

Godelier, M. (2007). Au fondement des sociétés humaines: ce que nous apprend l'anthropologie. Paris: Albin Michel.

Goffman, E. (1975). Stigmate: les usages sociaux des handicaps. trad. Alain Kibm. Paris: Éditions de Minuit.

Hannerz, U. (1983). Explover la ville: éléments d'anthropologie urbaine. Paris: Éditions de Minuit.

Héritier, F. (éd.) (2005). De la violence II. Paris: Odile Jacob.

Leach, E. R. (1972). Les systèmes politiques des hautes terres de Birmanie: analyse des structures sociales kachin. trad. Anne Guérin. Paris: F. Maspero.

Lenclud, G., Claverie, E., Jamin, J. (1984). Présentation: Une ethnographie de la violence est-elle possible? Études rurales, (95-96), 9-21.

Lévi-Strauss, C. (2001) [1971]. Race et histoire, Race et culture. Paris: Albin Michel - UNESCO. 
Lefebvre, H. (1974). Le droit à la ville suivi de Espace et Politique. Paris: Éditions du Seuil : Anthropos.

Marcus, G. E. (1995). Ethnography in/ Of the World System: The Emergence of Multi-sited Ethnography. Annual Review of Anthropology, 24, 995-117.

Meertens, D. (2001). Populations déplacées en Colombie et insertion urbaine. Annales de la recherche urbaine, 91, 118-127.

Malkki, L. H. (1995). Purity and exile : violence, memory, and national cosmology among Hutu refugees in Tanzania. Chicago: University of Chicago Press.

Minassian, G. (2011). Zones grises : quand les États perdent le contrôle... Paris: Autrement.

Monsutti, A. (2004). Guerres et migrations: réseaux sociaux et stratégies économiques des Hazaras d'Afghanistan. Neuchâtel: Éd. de l'Institut d'ethnologie.

Naranjo, G. G. (2004). Ciudades y desplazamiento forzado en Colombia. El reasentamiento de hecho y el derecho al restablecimiento en contextos conflictivos de urbanización. En M. N. Bello Albarracín (Comp.), Desplazamiento forzado. Dinámicas de guerra, exclusión y desarraigo (p. 281). Bogotá: Universidad Nacional de Colombia-ACNUR.

Ortiz, S. C. M. (1990). La violence en Colombie: racines historiques et sociales. trad. Sylvie Blaise. Paris: L'Harmattan.

Pécaut, D. (1994). Violence et politique: quatre éléments de réflexion à propos de la Colombie. Cultures \& Conflits, 13-14, 155-166.
Pinzón, O. N. M. (2007). Los jóvenes de "la loma": Altos de Cazucá y el paramilitarismo en la periferia de Bogotá. Maguaré, 21, 271-295.

Senado de la República de Colombia (2011). Ley 1448 de 2011 . Ley de víctimas y Restitución de tierras (10/06/2011). Recuperado de http://www.unidadvictimas.gov.co/es/ley-1448de-2011/13653

Senado de la República de Colombia (2005). Ley 975 de 2005. Ley de Justicia y Paz. (25/07/2005). Recuperado de https://www.fiscalia.gov.co/colombia/wp-content/uploads/2013/04/ Ley-975-del-25-de-julio-de-2005-concordada-con-decretos-y-sentencias-deconstitucionalidad.pdf

Senado de la República de Colombia (1997). Ley 387. Por la cual se adoptan medidas para la prevención del desplazamiento frzado; la atención, protección, consolidación y esta estabilización socioeconómica de los desplazados internos por la violencia en la República de Colombia. (18/07/1997). Recuperado de https://www.unidadvictimas.gov. $\mathrm{co} /$ sites/default/files/documentosbiblioteca/ley-387-de-1997.pdf

Simmel, G. (2010). Sociologie: étude sur les formes de la socialisation. Paris: PUF.

Sun, T. (2008). [vs VI-V s. av. J.-C.]. L'art de la guerre. Paris: Flammarion, Champs Classiques.

Salcedo, F. A. (2015). Victimas y trasegares: forjadores de ciudad en Colombia 20022005. Bogotá: Universidad Nacional de Colombia-Centro de Estudios So- territarias 40

EL DESPLAZAMIENTO FORZADO INTRAURBANO: UNA MODALIDAD DE MOVILIDAD RESIDENCIAL 
ciales (CES). Grupo Conflicto Social y Violencia.

Stepputat F., Sorensen N. et al. (2002). Vidas móviles y la gobernanza de la movilidad: poder, politicas e identidades en el campo del desplazamiento interno en América Latina. Copenhague: Center for Development Research.

TLFI, Trésor de la Langue Française Informatisé, (XIX-XX), ATILF, CNRS, université de Lorraine. Récupéré de http://atilf. atilf.fr/tlf.htm

Todorov, T. (2008). La peur des barbares: au-delà du choc des civilisations. Paris: Robert Laffont.

Zeiderman, A. (2013). Living dangerously: Biopolitics and urban citizenship in Bogotá, Colombia. American ethnologist, 40,71-87. 